\title{
Virtual Visitor's Behavior in Tourism Destinations’ Online Portals: Analysis of Spain.info Website*
}

\author{
Gloria Ocariz, Mikel Zurutuza, Fidel Rebon, Jon Kepa Gerrikagoitia, Aurkene Alzua-Sorzabal \\ CICtourGUNE, San Sebastián, Spain
}

\begin{abstract}
The incorporation of information technologies (ITs) in the tourism sector has enabled marketing actions to be enhanced through websites. In this context, destinations' online portals have become a key tool to promote territories. Vast amount of money is invested in developing these virtual sites and lately, also increasing interest has been put towards their performance analysis. This study has been applied to Spain.info website in order to track virtual visitors' digital footprint. The analysis conducted through the Destination Web Monitor (DWM) system has allowed taking into consideration the behavior of visitors in the website in order to obtain results on their interests when visiting the portal. The article mainly focuses on Brazil, Russia, India, and China (BRIC), considered as markets of opportunity for the tourism sector in Spain. Results provided insights on to whom, when, and how to develop potential e-marketing campaigns.
\end{abstract}

Keywords: destination website, virtual visitor behavior, digital footprint, BRIC countries

\section{Introduction}

The Internet and information technologies (ITs) have provided a global frame in which "data sharing and information retrieval" allow computer systems to exert their power in all the existing domains at any moment and in a large extent (Koubâa \& Andersson, 2009, p. 1).

Likewise, the Internet has become one of the main portals for communication, information, promotion, and sales, so that these activities must be adapted to the new ways of doing through online platforms.

In the tourism realm, destination management organizations (DMOs) have similarly adapted to the ITs' new reality. DMOs are responsible for the marketing and general management functions for the tourism destinations at any geographical level. Through the DMO's online portal, the destination has benefited from a streaming information and promotion tool which has enabled them to present the territory to prospective travelers. Thus, the website has become an embedded part of the DMO online marketing actions (Wang \& Fesenmaier, 2006).

\footnotetext{
* Acknowledgements: The authors would like to thank the managers of TOURSPAIN for their excellent cooperation and support for this study.

Gloria Ocariz, researcher, Tourism Systems in the Digital Age Area, CICtourGUNE.

Mikel Zurutuza, researcher, Tourism Systems in the Digital Age Area, CICtourGUNE.

Fidel Rebon, researcher, Tourism Systems in the Digital Age Area, CICtourGUNE.

Jon Kepa Gerrikagoitia, director of Tourism Systems in the Digital Age Area, CICtourGUNE.

Aurkene Alzua-Sorzabal, executive director, Tourism Systems in the Digital Age Area, CICtourGUNE.

Correspondence concerning this article should be addressed to Fidel Rebon, Mikeletegi Pasealekua, 71-3 20009 Donostia, Gipuzkoa, Spain. Email: fidelrebon@tourgune.org.
} 
Indeed, the Internet is considered one of the key channels for tourists to search information about a destination and hence, to connect the demand to the territories. Facing this panorama, the DMO should analyze the visitor digital footprint for it to be able to customize the online experience and adjust online marketing strategies to web users' preferences and search behavior.

DMOs' online portals are the core channels for communication with potential travelers on the trip planning phase. But they may also act for information retrieval once at the destination, and on the post trip stage, when travelers look for travel memories and experience sharing, thus building engagement among virtual visitors towards the destination (Xiang \& Gretzel, 2010).

This article aims at studying the core elements of web analytics obtained through the online track of digital footprint for the website Spain.info where the offer of Spain as a tourism destination is promoted. Further to this, the analysis goes in depth on the emerging countries' economies: Brazil, Russia, India, China's (BRIC) key interests on the destination web as a way of boosting special issues for these markets of opportunity.

This paper is structured as follows. The first section explains the importance of these economies as a growing market for the Spanish tourism. The next issue relates to the business intelligence (BI) tools that are to be the key instrument for information retrieval. The system which enables the capture of digital footprint is later explained in the methodology section as well as the structure of the website susceptible of analysis. The following section deals with the obtained results. Finally, conclusions and future works are discussed.

\section{BRIC Economies: Key Potential Markets for Tourism in Spain}

Worldwide tourism destinations are reaching a maturity phase confronting a vast competition among territories (Morgan, Pritchard, \& Piggott, 2002; Buhalis, 2000). In this scenario, of unceasing tourism growth and with the subsequent fierce rivalry amongst destinations, the need of looking for new markets to which direct the marketing strategies has become evident.

The country of Spain holds the fourth position in terms of tourism arrivals worldwide; but lately, it is facing the competition of emerging tourism territories which are reaching a stronger position in the tourism realm. In this scenario, its tourism destination website has become a key source of information for travelers visiting the country and a key tool for destination promotion.

Further to this, emerging markets, namely, BRIC, are consolidating their economies; this fact has boosted a general economic development which has encouraged outbound tourism within them.

Spain as a tourism destination is also benefiting from this exponential growth, hosting tourists coming from the BRIC markets. In fact, in the year 2012, tourism arrivals compounding BRIC economies experienced an exponential growth, reaching 1.8 million tourists, which represented $3 \%$ of the total tourism arrivals (IET, 2012). Equally, their tourism expenditure means a higher annual variation rate than the whole rest of the expenditure generated by tourists in the country.

Statistics show that BRIC economies may be a wide potential market to conduct customized marketing strategies on the destination website.

\section{BI for e-Marketing}

BI has been used in this study in order to obtain insights on website users' behavior for the portal Spain.info. BI provides an innovative process for tourism businesses and destinations to be proactive in a competitive environment. In fact, it facilitates the information-obtaining methods and supports decision-making in a changing environment (Alzua-Sorzabal, Gerrikagoitia, \& Torres-Manzanera, 2013; Shih, Liu, \& Hsu, 2010). 
It acts as a starting point for the areas of strategic management and e-Science, becoming a cost-effective way of information dissemination for decision makers (Teo \& Choo, 2001).

In the most technological arena, BI is considered the "engine room of interactive marketing", through which hectic amount of data is gathered and converted into detailed business information. Once the raw data are treated, it can be used for the retrieval of market behavior information, which may lead to the creation of customized target marketing campaigns (Stone \& Woodcock, 2014, p. 9).

\section{Methodology}

This section explains the website structure and content as well as the data that will be gathered by the system Destination Web Monitor (DWM).

\section{Spain.info Website Structure}

The destination online portal of Spain is offered in 16 languages, aiming at a diverse variety of publics (see Table 1).

Table 1

Languages of Spain.info Website

\begin{tabular}{|l|l|}
\hline Languages & \\
\hline Spanish & English \\
\hline German & French \\
\hline Dutch & Portuguese \\
\hline Danish & Italian \\
\hline Norwegian & Russian \\
\hline Polish & Finnish \\
\hline Swedish & Chinese \\
\hline Japanese & Korean \\
\hline
\end{tabular}

It can be stated that Spain.info also focuses on the BRIC markets; the languages available include those spoken in these countries, with the exception of India. However, India is also available on the menu for the country of origin selection, but information for this particular market is provided in English.

The key information of the website is gathered on the top of the page, ranged by put-down tabs which include the following sections: "What Are You Looking for", "Where to Go", "Spain for...", and "Practical Information”. These main sections include sub-sections that can be accessed by clicking on each tab.

In order to capture the data trail left by virtual visitors to the web Spain.info, Google Analytics statistics tool is used. Afterwards, the data obtained are processed by the DWM. This system is explained below.

\section{DWM}

The DWM has been defined by its authors as the "system to measure, analyze, and model the behavior of visitors in different virtual areas where a destination is promoted and with the objective of providing benchmarking ratios that facilitate strategic surveillance and intelligent marketing policies" (Alzua-Sorzabal et al., 2013, p. 5).

The scheme of the DWM fulfills all the levels of the Web Analytics Maturity Model (WAMM) (Gassman, 2008). This model suggests a set of best practices covering the full lifecycle of products and services which goes from the formation to distribution and maintenance. Web analytics tools provide response to questions such as: (1) fractional number of visits by nationality and location; (2) engine search references other websites; 
(3) direct traffic; (4) social networking; (5) number of unique users; (6) number of new visits versus number of recurrent visits; (7) number of hits per page; (8) number of visited pages; (9) pages viewed by language; (10) ratio of pages per visits; and (11) bounce rate, etc. (Peterson, 2006). Furthermore, the maturity level of the DWM enables the formulation of more complex questions, such as the ones showed in Table 2.

Table 2

Questions Answered by Applying KDD Techniques to DWM

\begin{tabular}{|l|l|}
\hline Questions & Technical \\
\hline What do our users when surfing the web? & Sequential patterns \\
\hline What do they like most and which least? & Association rules or patterns frequency \\
\hline Are there groups differentiated by origin? & Analysis of clustering and classification analysis \\
\hline What are the most common profiles by origin/topic? & Association rules or patterns frequency \\
\hline Are there behaviors differentiated by origin/topic? & Clustering and other statistical techniques \\
\hline What are the most common tour paths? & Sequential patterns \\
\hline $\begin{array}{l}\text { What is the user behavior over time? Comparison between } \\
\text { periods, trends... }\end{array}$ & Other statistical techniques \\
\hline What are the buying habits of tourists? & Analysis of classification and association rules or patterns frequently \\
\hline $\begin{array}{l}\text { What are the features they have in common successful } \\
\text { products and services? }\end{array}$ & $\begin{array}{l}\text { Association rules or most frequent patterns and other statical } \\
\text { techniques }\end{array}$ \\
\hline
\end{tabular}

\section{Results and Discussion}

This section shows the data obtained through the tracking of digital footprint which has been properly processed by DWM in order to obtain further insights on the web user's behavior.

The study has been conducted in the third quarter of the year 2014, gathering data from the 1st of July to the 30th of September.

Spain.info has received an average of 40,379 visits a day, each of them visiting two page-views per visit and with a length of around 1 minute and 52 seconds. The bounce rate is almost of 70\%; this fact could imply that: (1) the user does not find what he/she is looking for; (2) the web content does not reach his/her expectations; and (3) negative index-linking from search tools (see Table 3).

Table 3

General Data Summary

\begin{tabular}{ll}
\hline Data & Statistics \\
\hline Number of visits & $3,970,111$ \\
Number of visits/day & 40,379 \\
Page views & $8,644,788$ \\
Average page views/visit & 2.18 \\
Bounce rate (\%) & $68.42 \%$ \\
Average duration time/visit & $0: 1: 52$ \\
\hline
\end{tabular}

Visitors show a clear pattern which indicates that they often visit the site on working days, especially on Monday. In fact, it presents sharp drops every Saturday. The same pattern is registered for page views. Furthermore, it is confirmed that July is the month receiving the highest number of visits (see Figure 1).

New visits for the quarter stand for $81 \%$, facing the $19 \%$ that refers to recurrent visits. Considering that the analysis is conducted towards a destination website, the fidelization rate will be rather low, but it presents high rotation of users (see Figure 2). 


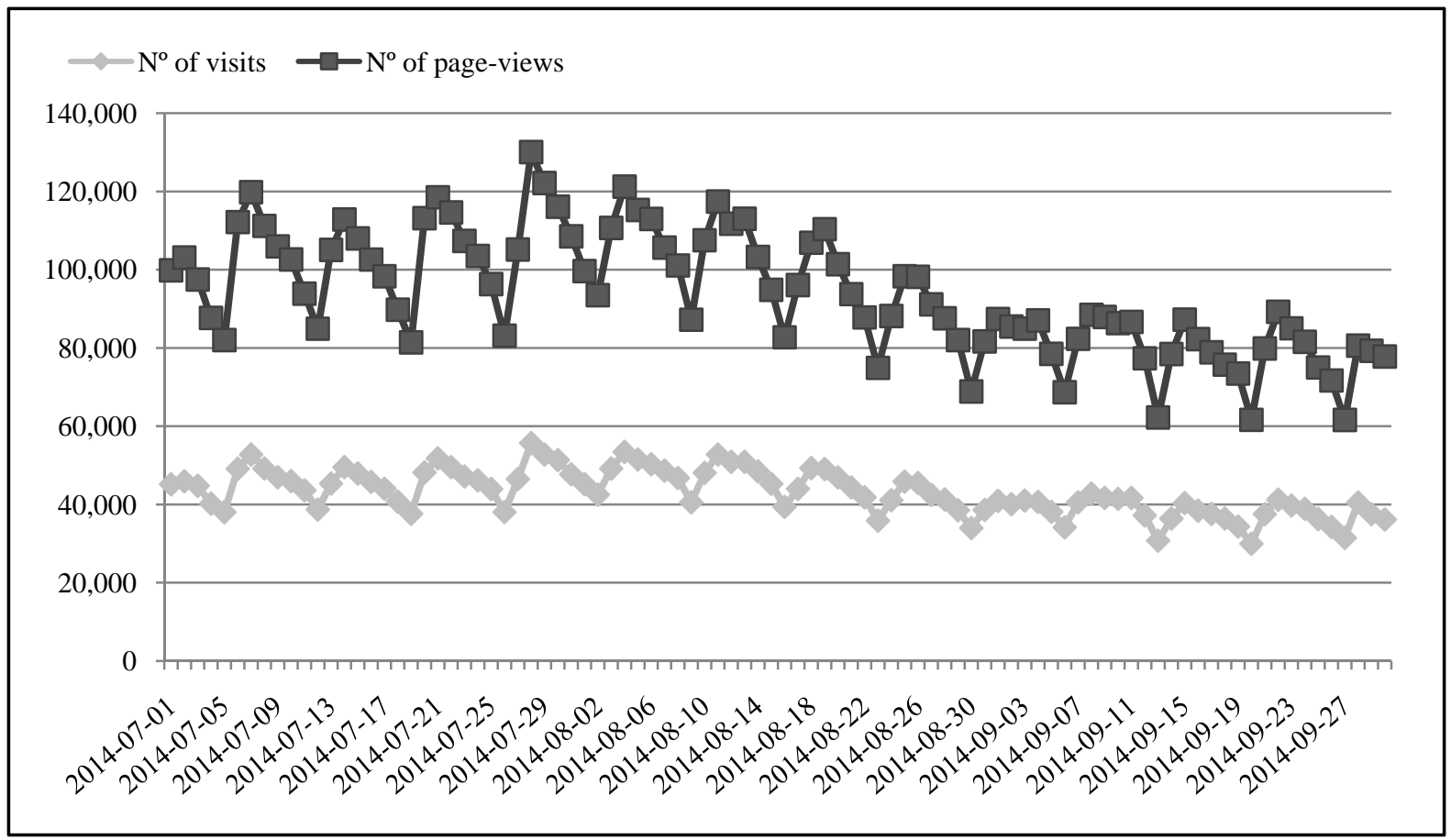

Figure 1. Visits and page views evolution.

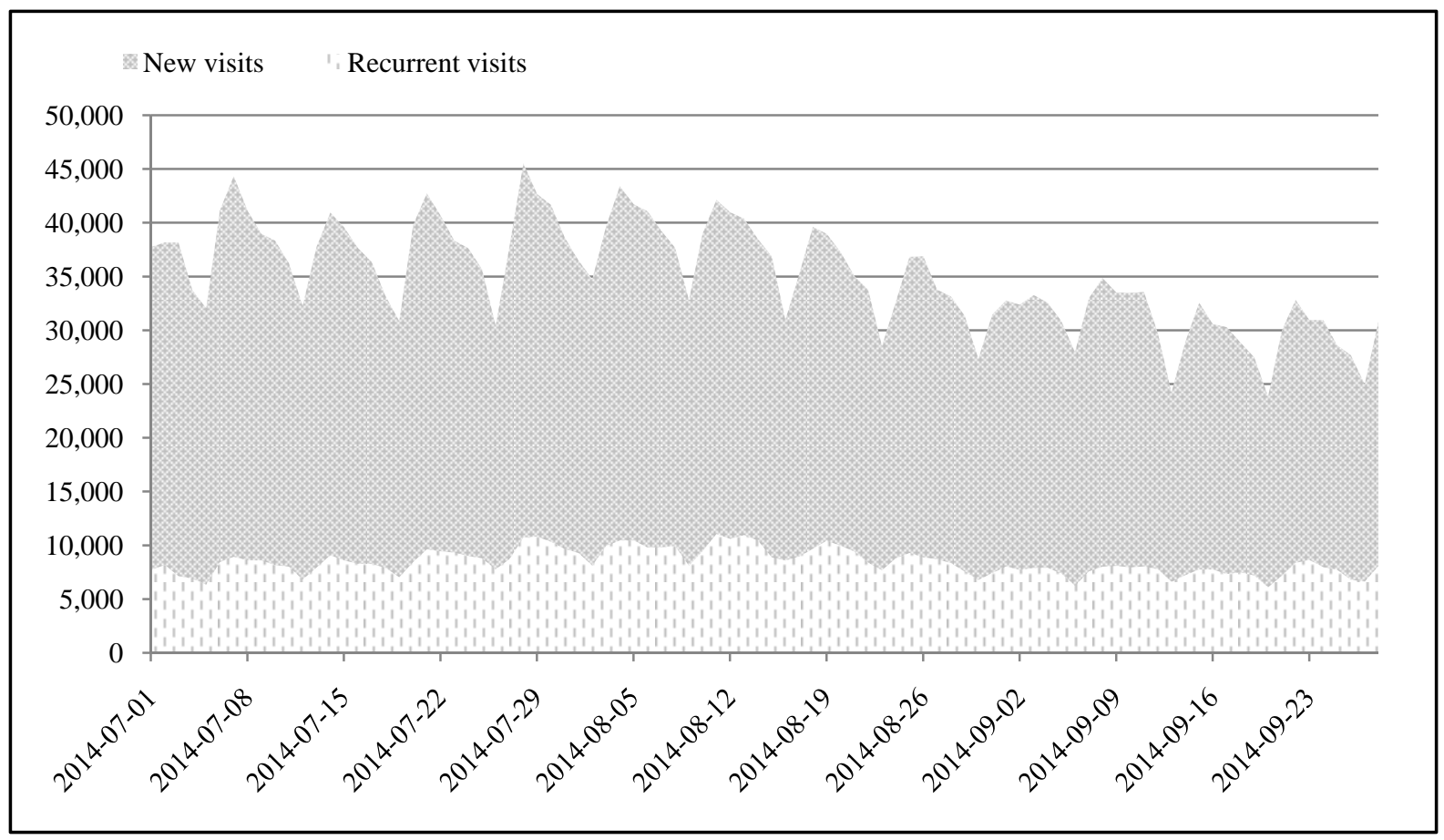

Figure 2. Evolution of new and recurrent visits.

Within the period, the number of visits shows a clear decrease along the months; July is the month with the highest amount of visits $(1,429,979)$, and August remains quite stable; however, the index decreases in September, barely reaching 1,138,024 visits (see Figure 3). 


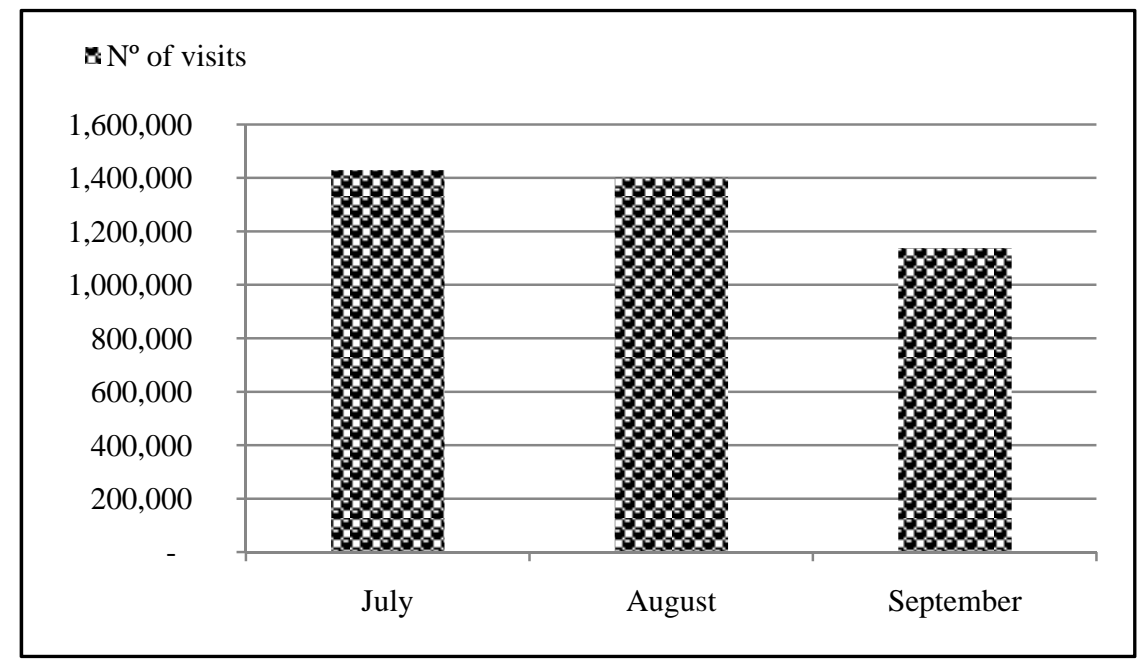

Figure 3. Number of visits per month.

The analysis has shown that the prime time for connection goes from 4:00 pm to 7:00 pm, reaching a peak at 5:00 pm.

Regarding pages that are more visited within the website, these include "What Are You Looking for" section (62\% of the visits) and "Practical Information" (16\%). Both of them are mostly visited in the Spanish and French versions. Within it, key sections are highlighted in blue (see Figure 4).

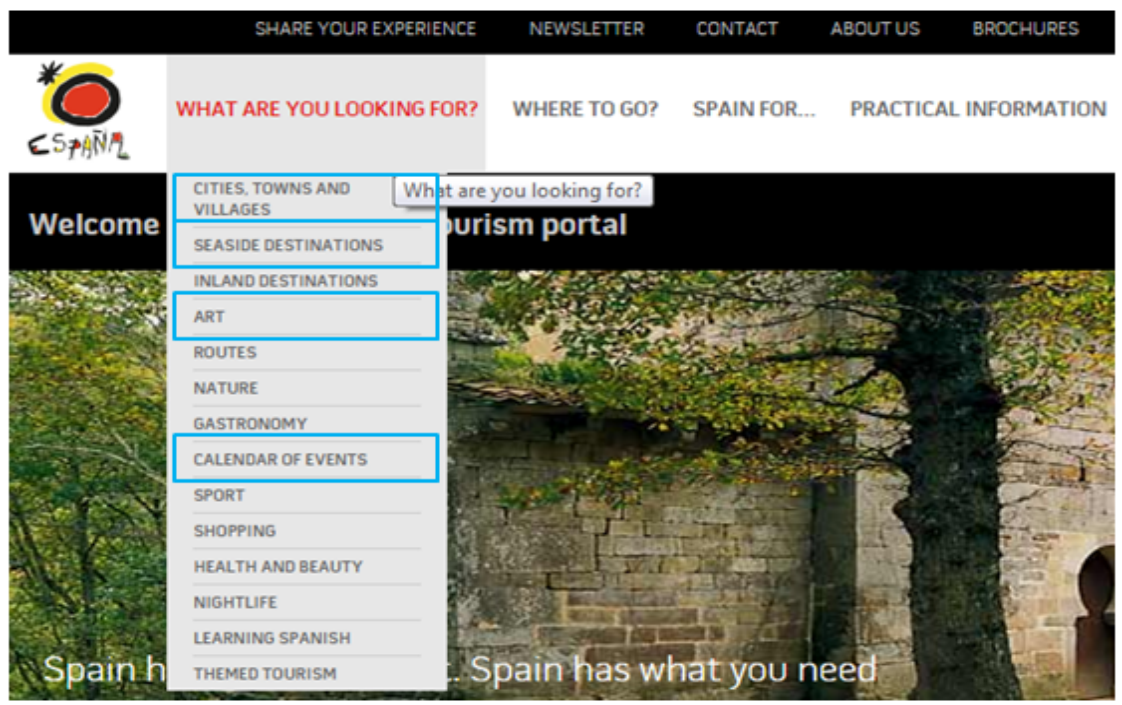

Figure 4. Spain.info front page.

Web pages within the site Spain.info are mainly visited by users from Madrid, Barcelona, and Valencia at the national level, and from Paris, Milan, and Rome at the international level.

Focusing on the BRIC countries as opportunity markets for the Spanish tourism sector, it is fair to mention that the Brazilian market is the one that represents the highest number of visits and page views as a whole. Figure 5 depicts the interest showed by the BRIC countries on each of the main sections. "What Are You Looking for" is largely considered, as it receives the highest amount of page views.

"Practical Information" is also fairly popular among BRIC countries. The remaining sections are apparently residual, as the amount of page views is barely relevant. 


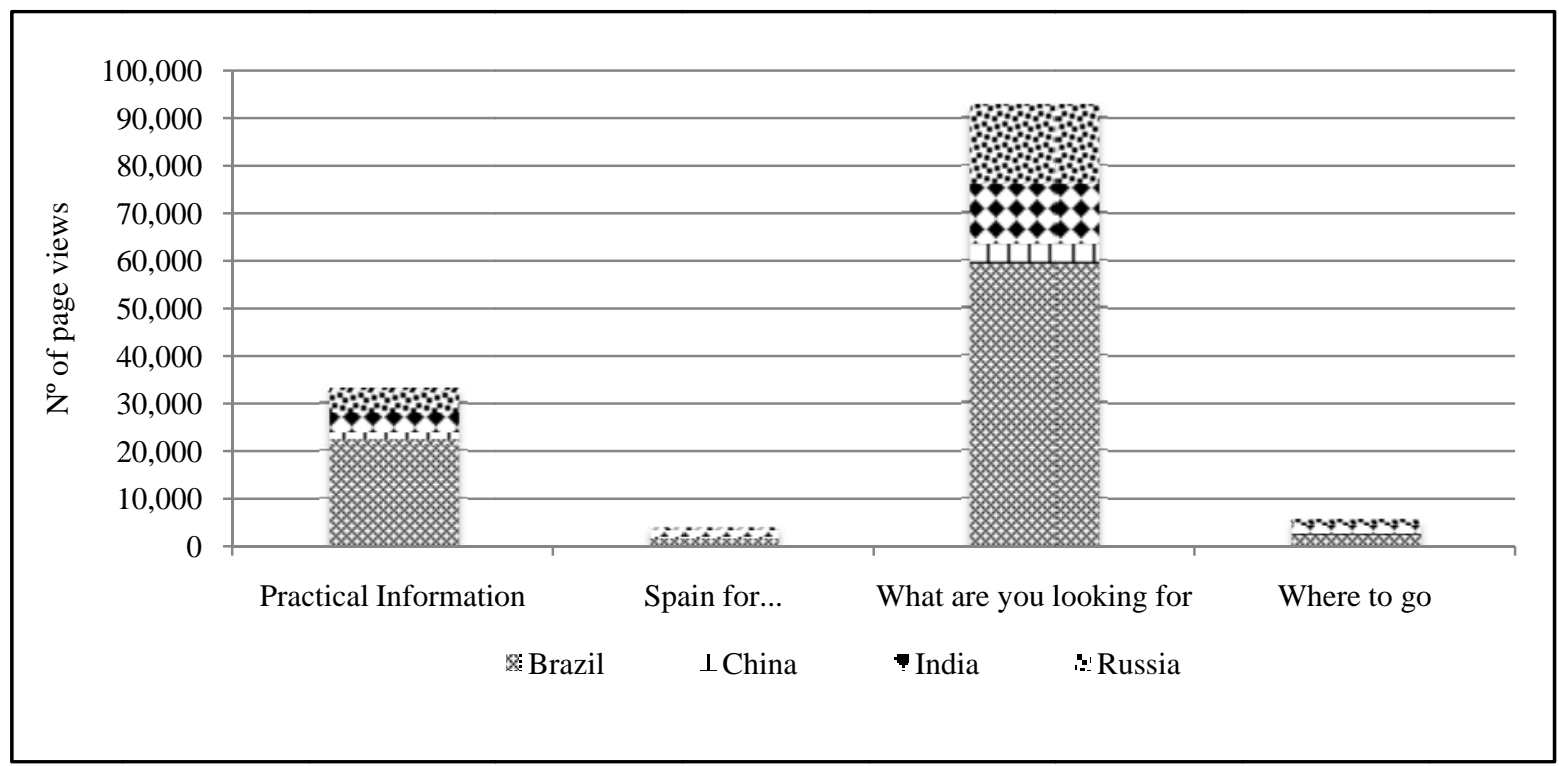

Figure 5. BRIC countries’ page views representativeness in each section.

In the same vein, the sub-sections included in "What Are You Looking for" are mainly visited by Brazil. This country shows a high interest in "cities", followed by "art", "agenda", and "gastronomy". Visitors from India also lean towards "cities”, "art”, and "agenda”. Russia’s visitors are mainly interested in "agenda", but the "cities" section also catches their attention. China focuses on "cities" followed by the section "art" (see Figure 6).

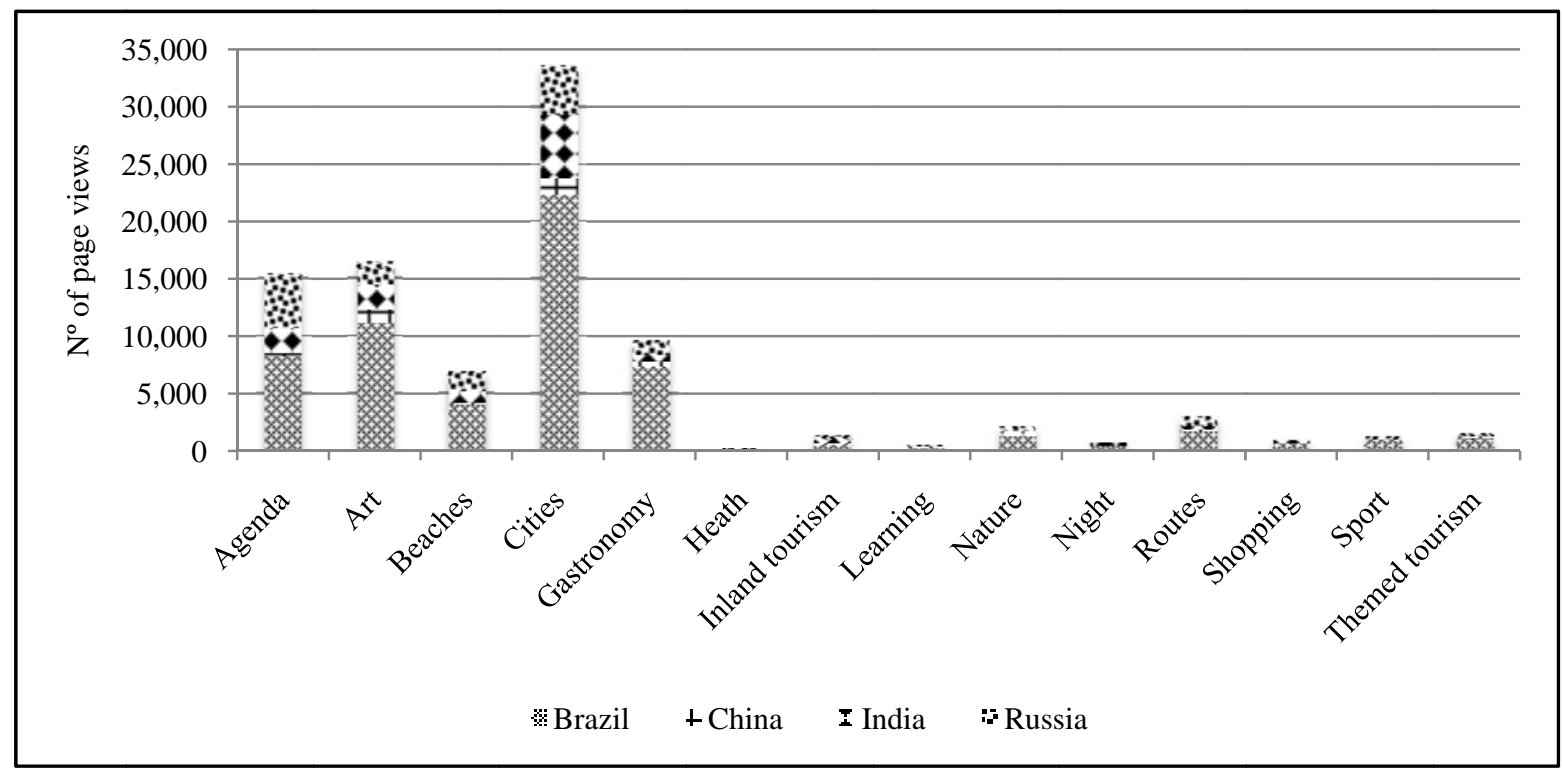

Figure 6. BRIC countries’ page views representativeness in the "What Are You Looking for" section.

Equally, within "Practical Information" section, Brazilians are those mostly visiting each of the sub-sections, except for the theme "accessible tourism" where the number is similar for Brazilians and Russians. India seems to view a similar number of pages in almost all sub-sections. However, "advices" section is by far the section where the focus of BRIC countries is reasonably high (see Figure 7). 


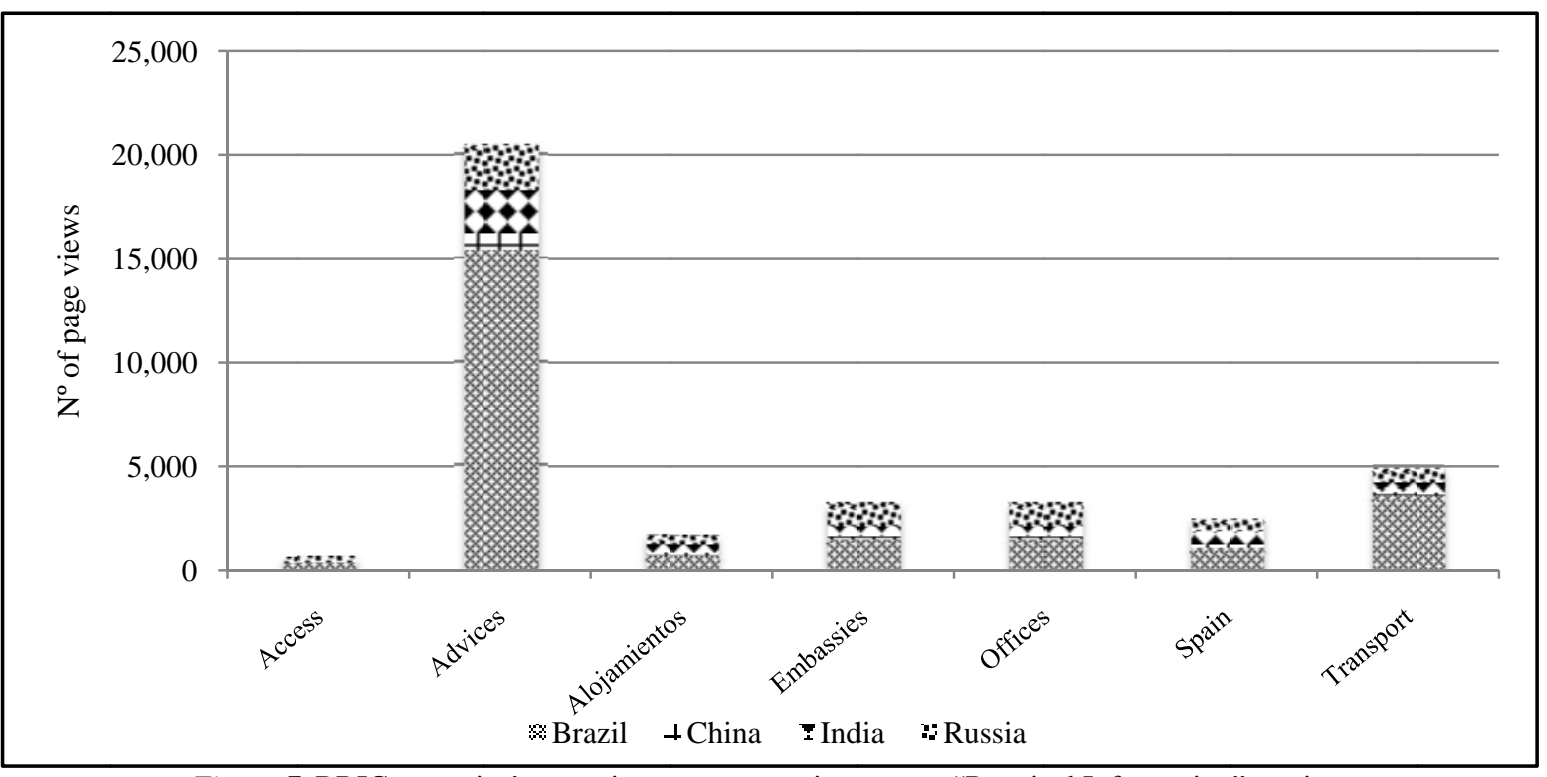

Figure 7. BRIC countries’ page views representativeness on "Practical Information” section.

\section{Conclusions and Future Work}

In this article, a study for discovering web users' behavior patterns has been conducted through means of digital footprint.

After conducting the analysis, it is perceived that the general interest showed by virtual visitors in Spain.info website could be improved. In fact, although daily visits are high, the time spent on site per visit is pretty short, counting for 1' 52 '' and two page views per visit, suggesting that the depth of the visit is rather short. Although this fact could also imply that the site is properly designed and so users can quickly find what they are searching, it must be noticed that it still remains fairly low.

On the other hand, web users mainly visit the site on working days and from 4:00 pm to 7:00 pm. This would condition the dates for launching marketing and promotional campaigns on the website.

The majority of the visitors are new (81\%); this figure shows the common pattern for an information and promotional website where fidelization rates are slightly low and instead, the rotation of visitors is high, contrasting with the usual behavior of an e-Shop.

Visits also show a drawback along the period, with the highest amount of visits during the month of July and the lowest occurring in September. This means that it would be interesting to carry out promotional activities during the high season periods, in this case July and August, as the user seems to let the holiday decision-making to the last moment.

Users' attention mainly concentrates on the sections "What Are You Looking for" and "Practical Information". These should be the areas within the website including the most representative elements of the destination, as it seems that they contain the most interesting pages for current users. Visitors' interest in the rest of the sections available in the menu has proved to be barely relevant. It could be interesting to redesign them in order to awake further attention among virtual visitors or analyze what may be failing with this content.

Regarding visitors' origin, the main capitals within the Iberian Peninsula and Europe represent the highest amount of the total visits. This point suggests that special attention should be put to develop marketing actions within those markets where the Spanish tourism brand is already well positioned. 
The study has mainly focused on users from the four emerging countries Brazil, Russia, India, and China, being considered opportunity markets for the country of Spain.

BRIC countries have also shown interest in "What Are You Looking for" section, followed by "Practical Information". Under the heading "What Are You Looking for", most of the sub-sections are highly consumed by Brazilians, and the same happens in "Practical Information". This means that within BRIC countries, Brazil is still the most representative market, so that it should be prioritized.

Further to this, BRIC countries have shown some different patterns; their interests are not always the same. Thus, although all of them depicted extended engagement on the sub-section "cities", Brazilians also leaned towards other key themes, not always coinciding with the interests of Russia, India, and China. This fact implies that particular communication campaigns focusing on different interests of virtual users can be implemented.

As a whole, these metrics can provide both new insights and feedback of online marketing campaigns. In summary, the DWM allows: (1) defining market segments; (2) considering different products for different segments; (3) increasing the number of followers (information adapted to the visitor profile); and (4) creating new brand target marketing campaigns.

Future research can be conducted by analyzing a longer period of time so that the results can be more accurate.

Accordingly, data could be compared with the latest marketing actions conducted by Turespaña and future research can make a review of whether it has a connection with the main interests showed by Spain.info users.

Apart from the limitations on the research, it is highlighted that the obtained results can be helpful for the destination portal in order to create marketing strategies depending on the users' interests regarding their patterns.

\section{References}

Alzua-Sorzabal, A., Gerrikagoitia, J. K., \& Torres-Manzanera, E. (2013). Opening and closing Internet booking channel for hotels: A first approximation. Tourism Management Perspectives, 5, 5-9.

Buhalis, D. (2000). Marketing the competitive destination of the future. Tourism Management, 21(1), 97-116.

Gassman, B. (2008). Introduction to the Gartner maturity model for web analytics. Gartner Group. Retrieved from https://www.gartner.com/doc/713211/overview-introduction-gartner-maturity-model

IET. (2012). Balance del turismo año 2012: Resultados de la actividad turística en España (p. 212).

Koubâa, A., \& Andersson, B. (2009). A vision of cyber-physical internet. Proceedings of the Workshop of Real-Time Networks (RTN 2009), Satellite Workshop to (ECRTS 2009).

Morgan, N., Pritchard, A., \& Piggott, R. (2002). New Zealand, 100\% pure. The creation of a powerful niche destination brand. The Journal of Brand Management, 9(4), 335-354.

Peterson, E. T. (2006). The big book of key performance indicators. Web analytics demystified.

Shih, M. J., Liu, D. R., \& Hsu, M. L. (2010). Discovering competitive intelligence by mining changes in patent trends. Expert Systems with Applications, 37(4), 2882-2890.

Stone, M. D., \& Woodcock, N. D. (2014). Interactive, direct, and digital marketing: A future that depends on better use of business intelligence. Journal of Research in Interactive Marketing, 8(1), 4-17.

Teo, T. S. H., \& Choo, W. Y. (2001). Assessing the impact of using the Internet for competitive intelligence. Information and Management, 39(1), 67-83.

Wang, Y., \& Fesenmaier, D. R. (2006). Identifying the success factors of web-based marketing strategy: An investigation of convention and visitors bureaus in the United States. Journal of Travel Research, 44(3), 239-249.

Xiang, Z., \& Gretzel, U. (2010). Role of social media in online travel information search. Tourism Management, 31(2), 179-188. 